Abbreviated Key Title: Sch J Med Case Rep

ISSN 2347-9507 (Print) | ISSN 2347-6559 (Online)

Journal homepage: https://saspublishers.com/sjmcr/

\title{
Retrograde Urethrography Examination in Penile Fracture: Case Report
} Iwan Purnomo Aji $^{1^{*}}$, Fikri Rizaldi ${ }^{2}$

${ }^{1}$ General Practitioner, Semen Gresik Hospital, Gresik, East Java, Indonesia

${ }^{2}$ General Urologist, Semen Gresik Hospital, Gresik, East Java, Indonesia

DOI: $10.36347 /$ sjmcr.2020.v08i10.017

| Received: 02.10.2020 | Accepted: 17.10.2020 | Published: 29.10.2020

*Corresponding author: Iwan Purnomo Aji

Abstract

Case Report

Penile fracture is an uncommon condition. Fracture of the penis is a tear in the tunica albuginea of the corpora cavernosa that may be associated with injury to the corpus spongiosum and urethra. We describe the case of a 51-yearold man who presented with acute penile pain, penile swelling, and a hematuria after a blunt trauma during sexual intercourse. Retrograde urethrography examination revealed extravasation from distal penile urethra into the cavernous structure. In cases of penile fracture, retrograde urethrography can be used for definitive diagnosis.

Keywords: Penile fracture, urethral injury, imaging, retrograde urethrography.

Copyright $(\mathbb{0} 2020$ The Author(s): This is an open-access article distributed under the terms of the Creative Commons Attribution 4.0 Internationa License (CC BY-NC 4.0) which permits unrestricted use, distribution, and reproduction in any medium for non-commercial use provided the original author and source are credited.

\section{INTRODUCTION}

Fracture of the penis is a tear in the tunica albuginea of the corpora cavernosa which may be associated with injury to the corpus spongiosum and urethra [1]. Diagnosis is usually clinical, and urethral injury should be suspected in the penile fracture, especially in those cases with bilateral cavernosal rupture [2].

If there are blood in the meatus, hematuria, and difficulty in voiding, an associated urethral injury should be considered. Immediate retrograde urethrography should be considered if the symptoms of urethral injury are present [3].

The aim of this paper is to present a case of penile fracture with associated urethral injury, diagnosed by retrograde urethrography.

\section{CaSe RePORT}

A male patient, aged 51, was came to emergency unit complaining of sudden loss of erection during sexual intercourse, penile swelling, hematuria, discoloration, disfigurement, and blood in the urethral meatus urethrorrhagia. These symptoms had emerged 6 hours earlier, and the patient was still able to void in small amounts, with blood present in his urine. During the physical examination, a hematoma in the ventral penile shaft, pain during palpation and urethrorrhagia were present (Figure-1). Patient's history and a physical examination indicated a penile fracture. The patient's retrograde urethrography revealed extravasation from distal penile urethra into the cavernous structure (Figure-2).

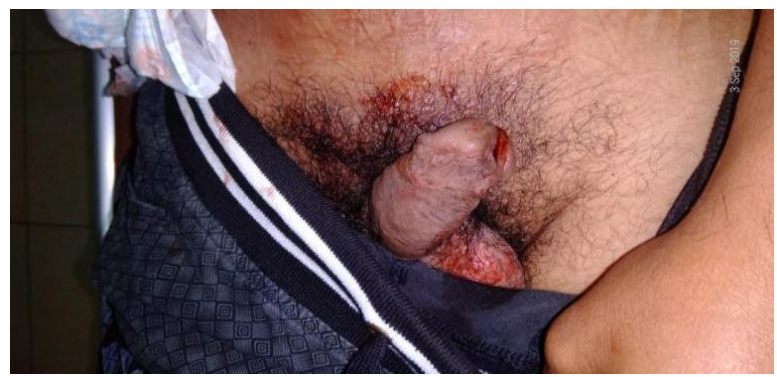

Fig-1: Hematoma in the ventral penile shaft

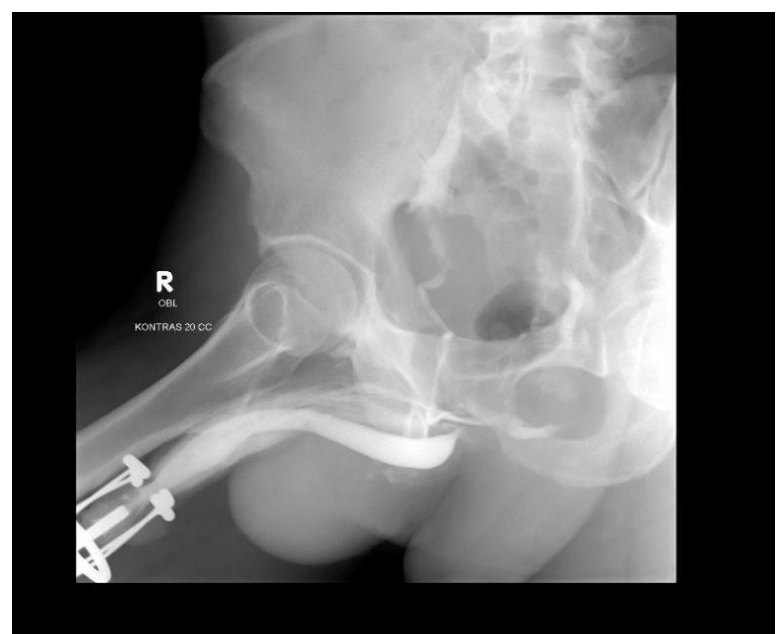

Fig-2: Urethral distal injury and rupture of corpus cavernosum in retrograde urethrography 


\section{DiscuSSION}

Penile fracture is a rare urological emergency. The tunica albuginea is a structure of great tensile strength that is able to withstand rupture at pressures up to $1500 \mathrm{mmHg}$. The tunica albuginea thins markedly during erection, which when combined with abnormal bending leads to excessive intracavernosal pressure and most often a transverse laceration of the proximal shaft $[4,5]$.

Penile fracture is diagnosed based on the patient's history, clinical examination, and the classic triad: audible "cracking" sound, followed by immediate detumescence and pain [3].

Penile fracture is mostly caused by the bending of the erect penis either over the pubic bone or the perineum of a sexual partner, during brutal masturbation, or penile kneading and snapping to achieve sudden detumescence. A transverse 1 to $2 \mathrm{~cm}$ tunical tear, usually unilateral, is present despite reports of tears in both corporeal bodies $[6,7]$.

Penile fracture diagnosis is mostly made clinically without the need for additional diagnostic tools as the fracture site is obvious. Cavernosography is to be considered in complicated cases due to the inherent contrast reaction fibrosis from extravasated contrast medium, infection, and priapism risk or only in deep dorsal vein rupture of the penis, which might be indistinguishable from cavernosal rupture [8].

Urethral bleeding and voiding incapacity can be symptoms of urethral injury. A retrograde urethrography should promptly be requested for effective treatment planning and, if the injury is present, simultaneous urethral repair during surgery [9].

In the penile fracture associated with urethral injuries, retrograde urethrography is an option. With better outcomes and fewer long-term complications, early surgery is preferable to conservative management.

\section{REFERENCE}

1. Eke N. Fracture of the Penis. Br J Surg. 2002;89:555-65.

2. Dever DP, Saraf PG, Catanese RP. Penile fracture: operative management and cavernosography. Urology. 1983;22:394-6.

3. Tsang T, Demby AM. Penile fracture with urethral injury. J Urol. 1992;147:466-8.

4. Jack GS, Garraway I, Reznichek R, Rajfer J. Current treatment options for penile fractures. Rev Urol. 2004; 6:114- 20.

5. Agarwal MM, Singh SK, Sharma DK, Ranjan P, Kumar S, Chandramohan V, Gupta N, Acharya NC, Bhalla V, Mavuduru R, Mandal AK. Fracture of the penis: a radiological or clinical diagnosis? A case series and literature review. Canadian Journal of Urology. 2009 Apr 1;16(2):4568.

6. Asgari MA, Hosseini SY, Safarinejad MR, Samadzadeh B, Bardideh AR. Penile fractures: evaluation, therapeutic approaches and long-term results. J Urol. 1996;155:148-9.

7. El-Taher AM, Aboul-Ella HA, Sayed MA, Gaafar AA. Management of penile fracture. J Trauma. 2004; 56:1138-40.

8. Koga S, Santo Y, Arakaki Y. Sonography in fracture of the penis. Br J Urol. 1993;72:228-9.

9. Agrawal SK, Morgan BE, Shafique M. Experience with penile fractures in Saudi Arabia. Br J Urol. 1991;67:644-6. 